\title{
Quantifying the risks of non-oncology phase I research in healthy volunteers: meta-analysis of phase I studies
}

\author{
Ezekiel J Emanuel, ${ }^{1,2}$ Gabriella Bedarida, ${ }^{3}$ Kristy Macci, ${ }^{3}$ Nicole B Gabler, ${ }^{4}$ Annette Rid, ${ }^{5}$ \\ David Wendler ${ }^{6}$
}

'Department of Medical Ethics and Health Policy, Perelman

School of Medicine, University of Pennsylvania, PA, USA

${ }^{2}$ Office of the Provost, University of Pennsylvania, PA, USA

${ }^{3} \mathrm{New}$ Haven Clinical Research Unit, Pfizer, New Haven, CT, USA

${ }^{4}$ Center for Clinical

Epidemiology and Biostatistics,

Perelman School of Medicine,

University of Pennsylvania

${ }^{5}$ Department of Social Science, Health \& Medicine, King's

College London, London, UK

${ }^{6}$ Department of Bioethics,

Clinical Center, National

Institutes of Health, Bethesda,

MD, USA

Correspondence to:

EJ Emanuel

vp-global@upenn.edu

Cite this as: BMJ 2015;350:h3271 doi: 10.1136/bmj.h3271

Accepted: 28 May 2015

\begin{abstract}
OBJECTIVE

To quantify the frequency and seriousness of adverse events in non-oncology phase I studies with healthy participants.

DESIGN

Meta-analysis of individual, healthy volunteer level data.

\section{SETTING}

Phase I studies with healthy volunteers conducted between September 2004 and March 2011 at Pfizer's three dedicated phase I testing sites in Belgium, Singapore, and the United States. These included studies in which drug development was terminated.

\section{PARTICIPANTS}

11028 participants who received the study drug in 394 distinct non-oncology phase I studies, which involved 4620 unique individuals. A total of 2460 (53.2\%) participants were involved in only one study, whereas others participated in two or more studies.

\section{MAIN OUTCOME MEASURES}

Adverse events classified as mild, moderate, and severe as well as serious adverse events-defined by the Food and Drug Administration as events that result in death, a life threatening event, admission to hospital, prolongation of existing hospital stay, a persistent or major disability, or a congenital anomaly or birth defect. Pfizer researchers of phase I trials determined adverse events, and serious adverse events were those filed with the FDA.
\end{abstract}

\section{RESULTS}

Overall, 4000 (36.3\%) participants who received the study drug experienced no adverse events and 7028 (63.7\%) experienced 24643 adverse events. Overall, $84.6 \%(n=20840)$ of adverse events were mild and $1.0 \%(n=255)$ were severe. $34(0.31 \%)$ serious adverse

\section{WHAT IS ALREADY KNOWN ON THIS TOPIC}

A key ethical concern about phase I research with healthy volunteers is that it exposes healthy individuals to serious risks for no clinical benefit

Data on the risks of phase I studies involving healthy volunteers are limited, as the existing studies have important limitations

\section{WHAT THIS STUDY ADDS}

Among 11028 healthy volunteers who received a study drug in non-oncology phase I research studies, $34(0.31 \%)$ experienced a serious adverse event, with no deaths or life threatening events

Half of the serious adverse events were not related to the study drug or a research procedure, and $84 \%$ of all adverse events were mild and $1 \%$ severe

The most common adverse events were headache, tiredness or drowsiness, diarrhea, nausea, and dizziness or lightheadedness events occurred among the 11028 participants who received the study agent, with no deaths or life threatening events. Of the 34 serious adverse events, 11 were related to the study drug and seven to study procedures, whereas 16 were unrelated to a study drug or procedure, including four that occurred when the participant was receiving a placebo. Overall, $24.1 \%$ $(n=5947)$ of adverse events were deemed to be unrelated to the study drug. With a total of 143 (36\%) studies involving placebo, $10.3 \%(n=2528)$ of all adverse events occurred among participants receiving placebo. The most common adverse events were headache $(12.2 \%, n=3017)$, drowsiness $(9.8 \%$, $n=2410)$, and diarrhea (6.9\%, $n=1698)$. Research on drugs for neuropsychiatric indications had the highest frequency of adverse events (3015 per 1000 participants).

\section{CONCLUSION}

Among 11028 healthy participants who received study drug in non-oncology phase I studies, the majority ( $85 \%$ ) of adverse events were mild. 34 ( $0.31 \%)$ serious adverse events occurred, with no life threatening events or deaths. Half of all adverse events were related to the study drug or to procedures.

Extrapolation of these data to other types of phase I studies, especially with biological agents, may not be warranted.

\section{Introduction}

One of the major ethical challenges of using human participants in research is exposing them to risks for the benefits of others. ${ }^{1}$ The most frequently cited example of this concern involves non-oncology phase I research conducted in healthy volunteers. This research is necessary to assess the safety and appropriate dosing of drugs before efficacy trials can proceed. Yet patient advocates, bioethicists, and researchers criticize phase I research because they claim that healthy participants are exposed to high risks of serious harms with no possibility of clinical benefit. ${ }^{2-7}$ This assumption is obviated when non-oncology phase I research poses few serious risks to participants but is reinforced by episodes such as the TeGenero case in which six healthy individuals in a phase I study experienced life threatening reactions. ${ }^{8-10}$

Robust studies exist on the risks and clinical benefits of phase I oncology trials that enroll patients with cancer. ${ }^{11} 12$ Yet despite more than 100000 healthy people participating annually in non-oncology phase I studies worldwide, little systematic research has quantified the risks. ${ }^{13-16}$ The few studies that do have important limitations. Firstly, the largest studies are from the mid-1990s and involve fewer than 1600 
participants each. Secondly, the studies tend to be published by the pharmaceutical industry, raising worries about selective publication. Thirdly, much of the published data are from Europe, reporting on homogenous populations-typically either students or pharmaceutical company employees-and might not be generalizable. Fourthly, some of the studies are based on surveys of investigators rather than reviews of actual clinical records of the participants. Fifthly, the existing studies use many different definitions and severity scales of adverse events and often report only "medically significant" ones.

We quantified the risks and serious adverse events in non-oncology phase I research studies involving healthy volunteers. We addressed the limitations of previous studies by comprehensively reviewing all the clinical and other records that were systematically and consistently collected in an electronic database for healthy volunteers who participated in all non-oncology phase I research studies of one drug company between 2004 and 2011. This included study drugs in which development was subsequently terminated.

\section{Methods}

The academic researchers from the National Institutes of Health, University of Pennsylvania, and King's College London proposed to Pfizer to review the adverse events of its non-oncology phase I studies involving healthy volunteers. To avoid any selection bias of the studies to be evaluated, the study involved all nononcology phase I studies, enrolling healthy volunteers-not patients-over an extended period. The study was retrospective so that knowledge of the study would not influence Pfizer clinicians' determinations of adverse events or their causal relation to the study agent. An independent contractor paid by the $\mathrm{NIH}$ extracted the data from the Pfizer database, which were then analyzed by the researchers from the NIH, University of Pennsylvania, and King's College London who had complete control of the data.

\section{Study setting}

We reviewed all non-oncology phase I trials in adults conducted by Pfizer at its three phase I trial centers worldwide between the initiation of its electronic records system in September 2004 and study completion in March 2011. Excluded were phase I studies in patients and phase I/II, phase II, and phase III trials. Overall, 471 trials were conducted during the study period of which 77 trials were excluded: 33 were methodology trials that entailed no study drugs being administered, six were cancelled before drugs were administered, 30 were initiated on paper records before the computerized data collection was installed, and eight were phase I trials conducted with patients. The final sample included 394 trials. All these studies had been approved by institutional review boards or research ethics committees.

Typically, Pfizer advertises that a trial is available and individuals schedule screening visits at one of the centers. Advertisements are posted on Pfizer's website and placed in local newspapers. Enrolled individuals are paid based on the reviewing institutional review boards' estimation of the participants' time and the number of procedures involved, but not paid based on risk. Individuals who participated in previous phase I studies cannot enroll in another phase I trial until at least 30 days or five drug half lives after the last dosing of the drug (whichever is longer) to preclude drugdrug interactions. Thus no healthy volunteer could be in two studies at once in trials conducted by Pfizer. In the 394 studies reported here, no healthy volunteer was enrolled in a subsequent Pfizer study within 30 days or less.

Since 2004, Pfizer maintains a comprehensive, centralized computerized data warehouse of all data from the three phase I trial centers. All clinical, laboratory, radiological, physical (for example, blood pressure), and participant reported symptoms, participant questionnaire responses, investigator identified symptoms, and other data are collected into the database from all three centers in the same standardized and systematic fashion. At the time of an adverse event, trained research staff directly enter data on the event. Based on timing, the nature of the adverse event, and other factors, the team of investigators determines whether the adverse event was related to the phase I agent or to a research procedure before unblinding to identify whether the participant was receiving the active study drug or placebo. All data are updated and backed up each night. Pfizer adheres to established good practices in technical and organizational data protection.

\section{Patient involvement}

There was no patient or public involvement in the design of the phase 1 studies in themselves. Patients are also routinely involved in the development of Pfizer's research portfolio and the design of later phase, phase II and III, trials.

\section{Recording and assessment of adverse events}

For a typical study, each healthy volunteer is monitored every day of their stay in the phase 1 research unit, and laboratory and other clinical data, such as electrocardiography, are collected as specified in the study protocol. All data and any abnormal findings, such for liver function tests, are recorded. Typically, while staying in the research unit, participants are asked three times a day about potential adverse events using neutral, non-leading language. These assessments usually occur before dosing with the study agent, and in the afternoon and evening. In addition, the research unit has signage stressing the importance of reporting all symptoms and adverse events. Once discharged, participants are monitored until at least 30 days after the last dosing or five half lives of the drug (whichever is longer).

All the phase I informed consent documents emphasize that it is important for participants to report symptoms and adverse events, and that they will not be penalized if they report such events. Typical 
language is: "In this study, these medications will be given together for the first time. Thus we cannot predict if the side effects you may get will be the same as these mentioned here or different or more severe. Thus it is very important that you report any changes in your health, however minor, to the study staff so your health can be carefully monitored." To reduce if not eliminate any incentives to hide adverse events, participants are informed that they will not be financially penalized if they are withdrawn from the study because of adverse events.

Pfizer clinic staff initially assess the adverse events, whether a symptom or a laboratory finding, and classify them as mild, moderate, or severe based on impact on daily activities. These classifications are confirmed by the Pfizer primary investigator. To avoid bias, assessments and classifications of adverse events are made with the Pfizer clinic staff and primary investigator blinded to whether the participant is receiving the study agent or placebo. Classifications of whether the study drug caused the adverse events are divided into two categories: did not cause the adverse event, or uncertain or caused the adverse event. Thus uncertainty in causation is categorized as causing the adverse event.

\section{Data extraction and control}

An independent consultant with experience working on pharmaceutical company data and paid by the NIH verified and extracted the data from the Pfizer database into a separate file according to pre-established data fields. All participant and adverse event data were deidentified. The raw data were delivered to the research teams at NIH, University of Pennsylvania, and King's College London. Pfizer researchers assisted by describing the conduct of phase I studies, the process of monitoring participants, data fields, classifications of adverse events, clarifying data elements as needed, and other factors. The data were maintained, controlled, analyzed, and interpreted by researchers at the NIH, University of Pennsylvania, and King's College London.

\begin{tabular}{|c|c|c|c|c|}
\hline \multirow[b]{2}{*}{ Characteristics } & \multicolumn{3}{|c|}{ Location of phase I test sites } & \multirow[b]{2}{*}{$\begin{array}{l}\text { Total* } \\
(\mathrm{n}=11028)\end{array}$} \\
\hline & $\begin{array}{l}\text { USA } \\
(n=3889)\end{array}$ & $\begin{array}{l}\text { Belgium } \\
(\mathrm{n}=3869)\end{array}$ & $\begin{array}{l}\text { Singapore } \\
(n=3270)\end{array}$ & \\
\hline $\begin{array}{l}\text { Median (interquartile range) } \\
\text { age (years) }\end{array}$ & $35(27-43)$ & $35(28-43)$ & $29(24-35)$ & $33(26-41)$ \\
\hline Men & $3407(87.6)$ & $3314(85.7)$ & $3021(92.4)$ & $9742(88.3)$ \\
\hline Women & $458(11.8)$ & $555(14.3)$ & $249(7.6)$ & $1262(11.4)$ \\
\hline \multicolumn{5}{|l|}{ Race/ethnicity: } \\
\hline White & $1017(26.2)$ & 3557 (91.9) & $5(0.2)$ & $4579(41.5)$ \\
\hline Black & $1840(47.3)$ & $210(5.4)$ & $10(0.3)$ & $2060(18.7)$ \\
\hline Hispanic & $644(16.6)$ & $0(0)$ & $0(0)$ & $644(5.8)$ \\
\hline Asian & $226(5.8)$ & $6(<0.2)$ & 3224 (98.6) & $3456(31.3)$ \\
\hline Other & $138(3.5)$ & $96(2.5)$ & $31(0.9)$ & $265(2.4)$ \\
\hline $\begin{array}{l}\text { Previous participation in } \\
\text { research }\end{array}$ & $3093(79.5)$ & $3164(81.8)$ & $2311(70.7)$ & $8568(77.7)$ \\
\hline History of smoking & $520(13.4)$ & $1172(30.3)$ & $1200(36.7)$ & $2892(26.2)$ \\
\hline History of alcohol use & $1120(28.8)$ & $2731(70.1)$ & $763(23.3)$ & $4614(41.8)$ \\
\hline
\end{tabular}

*Demographic data are missing from two protocols for 24 participants.

\section{Classification of trials and adverse events}

Trials were grouped by Pfizer and verified by the researchers at NIH, University of Pennsylvania, and King's College London as to whether the agent was previously approved by the Food and Drug Administration but was, for example, in a new formulation or delivery vehicle; the agent was investigational-that is, was a new compound; or whether the trial combined an FDA approved agent with a new, investigational agent. Agents were categorized into type of agent-small molecule, biologic, or other. Further, Pfizer groups trials according to the main treatment area targeted by the agent.

A serious adverse event is defined by FDA regulations as an event that results in death, a life threatening event, admission to hospital, prolongation of existing hospital stay, a persistent or major disability, or a congenital anomaly or birth defect. ${ }^{17}$ In addition, the severity of adverse events is classified into three categories routinely used in phase I studies, although they are not defined by the FDA: mild, moderate, or severe. A mild adverse event does not interfere with a participant's usual functioning; an example is a high blood pressure reading that the participant is unaware of. A moderate event interferes to some extent with a participant's usual functioning; an example is a migraine headache. A severe adverse event interferes in a major way with a participant's basic daily functioning; for example, a broken finger. Thus, seriousness and severity are independent assessments. Some adverse events, such as increased liver enzyme levels without symptoms could be serious based on the FDA definition, but of mild severity. Conversely, a severe adverse event might not be serious.

\section{Statistical analysis}

We describe categorical data as numbers (percentages) and continuous data as medians (interquartile ranges). To compare groups we used the $\chi^{2}$ test and Kruskal-Wallis test for categorical and continuous data, respectively. All participant level analyses were conducted at the level of the dosed participant, with either placebo or active drug $(n=11028)$, not the number of doses of the research agent. We considered a $\mathrm{P}$ value $<0.05$ to be significant. All analyses were conducted in Stata 13 (Stata, College Station, TX).

\section{Results}

Characteristics of research studies and participants Overall, 394 non-oncology phase I trials involving 11028 participants who received the study agent were eligible (table 1). Of the 11028 participants, 4620 were unique study participants-separate individuals, some participants were enrolled in multiple trials over the seven years of data collection. Overall, 2460 (53.2\%) healthy volunteers participated in one study, with the remainder participating in two or more studies. The dosed participants were approximately evenly divided among the three phase I testing centers in Belgium, Singapore, and the United States (table 1). 
The median age was 33, with $9742(88.3 \%)$ participants being men (table 1). The median age for women was 35 years and for men was 32 years. American participants were significantly less likely to smoke (520 (13.4\%) $v 1172$ (30.3\%) compared with Belgians, and 520 (13.4\%) v 1200 (36.7\%) compared with Singaporeans, $\mathrm{P}<0.001)$ and significantly less likely to consume alcohol (1120 (28.8\%) $v$ 2731 (70.1\%) compared with Belgians, $\mathrm{P}<0.001)$.

Of the 11028 participants in these non-oncology phase I trials, 2552 (23.1\%) were administered a previously approved FDA agent, $7049(63.9 \%)$ received an investigational agent, and 1427 (12.9\%) received a combination of an FDA approved and investigational agent (table 2). Overall, 10660 (97.0\%) participants were given a small molecule agent, with the rest receiving biologic

\begin{tabular}{|c|c|c|c|c|}
\hline \multirow[b]{2}{*}{ Characteristics } & \multicolumn{3}{|c|}{$\begin{array}{l}\text { No (\%) of participants receiving study drug by test } \\
\text { site location }\end{array}$} & \multirow{2}{*}{$\begin{array}{l}\text { Total (\% } \\
\text { are for } \\
\text { column) }\end{array}$} \\
\hline & USA & Belgium & Singapore & \\
\hline \multicolumn{5}{|c|}{ Previously FDA approved agent } \\
\hline Total & $1143(44.8)$ & $460(18.0)$ & $949(37.2)$ & $2552(23.1)$ \\
\hline \multicolumn{5}{|l|}{ Type of agent: } \\
\hline Small molecule & $1143(44.8)$ & $460(18.0)$ & $949(37.2)$ & 2552 \\
\hline Biologic & $0(0)$ & $0(0)$ & $0(0)$ & 0 \\
\hline \multicolumn{5}{|l|}{ Primary treatment area: } \\
\hline Neurological/psychiatric & $449(71.6)$ & $116(18.5)$ & $62(9.9)$ & 627 \\
\hline Cardiovascular & $316(48.7)$ & $0(0)$ & $333(51.3)$ & 649 \\
\hline Pulmonary & $0(0)$ & $0(0)$ & $202(100)$ & 202 \\
\hline Gastrointestinal & $0(0)$ & $0(0)$ & $0(0)$ & 0 \\
\hline Gynecological & $52(32.5)$ & $60(37.5)$ & $48(30.0)$ & 160 \\
\hline Rheumatological & $90(30.1)$ & $149(49.8)$ & $60(20.1)$ & 299 \\
\hline Infectious disease & $122(34.3)$ & $77(21.6)$ & $157(44.1)$ & 356 \\
\hline Other & $114(44.0)$ & $58(22.4)$ & $87(33.6)$ & 259 \\
\hline \multicolumn{5}{|l|}{ Investigational agent } \\
\hline Total & $2361(33.5)$ & $2988(42.4)$ & $1700(24.1)$ & $7049(63.9)$ \\
\hline \multicolumn{5}{|l|}{ Type of agent: } \\
\hline Small molecule & $2234(33.3)$ & $2782(41.4)$ & $1700(25.4)$ & 6716 \\
\hline Biologic & $127(38.1)$ & $206(61.9)$ & $0(0)$ & 333 \\
\hline \multicolumn{5}{|l|}{ Primary treatment area: } \\
\hline Neurological/psychiatric & $616(40.2)$ & $547(35.7)$ & $370(24.1)$ & 1533 \\
\hline Cardiovascular & $830(62.4)$ & $353(26.5)$ & $148(11.1)$ & 1331 \\
\hline Pulmonary & $0(0)$ & $369(58.2)$ & $265(41.8)$ & 634 \\
\hline Gastrointestinal & $0(0)$ & $207(55.6)$ & $165(44.4)$ & 372 \\
\hline Gynecological & $40(13.4)$ & $180(60.2)$ & $79(26.4)$ & 299 \\
\hline Rheumatological & $272(35.1)$ & $207(26.7)$ & $296(38.2)$ & 775 \\
\hline Infectious disease & $355(35.1)$ & $525(52.0)$ & $130(12.9)$ & 1010 \\
\hline Other & $248(22.6)$ & $600(54.8)$ & $247(22.6)$ & 1095 \\
\hline \multicolumn{5}{|c|}{ Combination of FDA approved and investigational agents } \\
\hline Total & $385(27)$ & $421(30)$ & $621(44)$ & $1427(12.9)$ \\
\hline \multicolumn{5}{|l|}{ Type of agent: } \\
\hline Small molecule & $350(25.1)$ & $421(30.3)$ & $621(45.6)$ & 1392 \\
\hline Biologic & $35(100)$ & $0(0)$ & $0(0)$ & 35 \\
\hline \multicolumn{5}{|l|}{ Primary treatment area: } \\
\hline Neurological/psychiatric & $40(52.6)$ & $0(0)$ & $36(47.4)$ & 76 \\
\hline Cardiovascular & $225(52.7)$ & $86(20.1)$ & $116(27.2)$ & 427 \\
\hline Pulmonary & $0(0)$ & $48(40.0)$ & $72(60.0)$ & 120 \\
\hline Gastrointestinal & $0(0)$ & $0(0)$ & $0(0)$ & 0 \\
\hline Gynecological & $0(0)$ & $0(0)$ & $0(0)$ & 0 \\
\hline Rheumatological & $12(31.6)$ & $0(0)$ & $26(68.4)$ & 38 \\
\hline Infectious disease & $108(14.1)$ & $287(37.5)$ & $371(48.4)$ & 766 \\
\hline Other & $0(0)$ & $0(0)$ & $0(0)$ & 0 \\
\hline
\end{tabular}

agents. The three leading clinical areas of research were cardiovascular (2407 (21.8\% of all participants), neuropsychiatric (2236, 20.3\%), and infectious diseases (2132, $19.3 \%$, table 2 ).

\section{Adverse events}

Of 11028 participants who received the study agent, 4000 (36.3\%) experienced no adverse events, whereas the remainder $(7028,63.7 \%)$ experienced a cumulative 24643 adverse events (table 3 ). A total of $20 \%$ of participants had one adverse reaction, 13\% two adverse reactions, 9\% three adverse reactions, and one participant 31 (the maximum) adverse reactions (figure). The median number of adverse events per dosed participants was 1 (interquartile range $0-3$ ). Of all adverse events, 4596 (18.7\%) occurred on the first day of the study.

The most adverse events were experienced in neuropsychiatric studies $(6741,27.4 \%)$ and in infectious disease studies (5144, 20.9\%, table 3). The most common adverse events per 1000 participants were in neuropsychiatric studies (3015 per 1000 participants), with gastrointestinal and gynecological studies second and third (2609 and 2538 per 1000, respectively).

Among the 368 dosed participants in studies involving biologics, a total of 949 adverse events occurred. Across all studies, the most common were headache (3017, 12.2\%), tiredness or drowsiness (2410, 9.8\%), diarrhea (1698, 6.9\%), nausea (1453, (5.9\%), dizziness or lightheadedness (1333, 5.4\%), and vomiting (483, 2.0\%, table 3).

Of the 24643 adverse events, 20840 (84.6\%) were mild (that is, did not interfere with usual functioning), 13548 (4.4\%) were moderate, and 255 (1.0\%) were severe (that is, interfered significantly with the participants' functioning, table 4). Among volunteers receiving biologic agents, 12 (1.3\%) of all the adverse events were severe. Severity of adverse events did not differ significantly between healthy volunteers who participated in only one study and those who participated in multiple studies (table 4). In blinded assessments of causality, $18696(75.9 \%)$ of the adverse events were deemed to be caused by the study drug (table 4).

In most cases $(24335,98.7 \%)$ no action was needed to deal with the adverse event: neither was the study drug stopped nor a medical intervention needed to mitigate the adverse event. For 0.8\% (190 of 24643) adverse events, there was permanent discontinuation of the study drug but no treatment, and for $0.1 \%$ (24 of 24 643) there was temporary discontinuation of the study drug, with no treatment (table 4). In 0.3\% (67 of 24643) adverse events, there was permanent discontinuation of the study drug and needed treatment.

\section{Adverse events involving placebo}

Of all adverse events, 685 (2.8\%) occurred before dosing of the study drug, with 475 (69.3\%) mild and five (0.7\%) severe (table 4).

Overall, 143 (36\%) studies involved placebo, with $2649(24.0 \%)$ of 11028 participants who received 
Table 3 | Frequency and severity of adverse events in non-oncology phase I research studies

\begin{tabular}{lllll} 
Characteristic of studies & \multicolumn{2}{l}{ Adverse events } & $\begin{array}{l}\text { Total }(\% \text { are } \\
\text { for column) }\end{array}$ \\
\cline { 2 - 5 } No $(\%)$ of adverse events & & Moderate & Severe & \\
\hline Total & $20840(84.6)$ & $3548(14.4)$ & $255(1.0)$ & $24643(100)$ \\
\hline Type of agent: & & & \\
\hline Small molecule & $20191(85.2)$ & $3260(13.8)$ & $243(1.0)$ & $23694(96.1)$ \\
\hline Biologic & $649(68.4)$ & $288(30.3)$ & $12(1.3)$ & $949(3.9)$ \\
\hline Primary treatment area: & & & \\
\hline Neurological/psychiatric & $5487(81.4)$ & $1134(16.8)$ & $120(1.8)$ & $6741(27.4)$ \\
\hline Cardiovascular & $3775(86.4)$ & $557(12.7)$ & $39(0.9)$ & $4371(17.7)$ \\
\hline Pulmonary & $1603(85.3)$ & $270(14.4)$ & $6(0.3)$ & $1879(7.6)$ \\
\hline Gastrointestinal & $860(88.4)$ & $106(10.9)$ & $7(0.7)$ & $973(3.9)$ \\
\hline Gynecological & $963(82.7)$ & $198(17.0)$ & $4(0.3)$ & $1165(4.7)$ \\
\hline Rheumatological & $1425(85.2)$ & $237(14.2)$ & $11(0.7)$ & $1673(6.8)$ \\
\hline Infectious disease & $4305(83.7)$ & $777(15.1)$ & $62(1.2)$ & $5144(20.9)$ \\
\hline Other & $2422(89.8)$ & $269(10.0)$ & $6(0.2)$ & $2697(10.9)$ \\
\hline No & & &
\end{tabular}

No of adverse events per 1000 participants receiving study drug

Primary treatment area:

\begin{tabular}{lllll}
\hline Neurological/psychiatric & 2454 & 507 & 54 & 3015 \\
\hline Cardiovascular & 1568 & 231 & 16 & 1816 \\
\hline Pulmonary & 1677 & 282 & 6 & 1965 \\
\hline Gastrointestinal & 2312 & 285 & 19 & 2609 \\
\hline Gynecological & 2098 & 431 & 9 & 2538 \\
\hline Rheumatological & 1281 & 213 & 10 & 1504 \\
\hline Infectious disease & 2019 & 364 & 29 & 2413 \\
\hline Other & 1789 & 199 & 4 & 1992 \\
\hline No (\%) of most common adverse events: & & & \\
\hline Headache & $2227(73.8)$ & $778(25.8)$ & $12(0.4)$ & $3017(12.2)$ \\
\hline Tiredness/drowsiness & $2069(85.9)$ & $292(12.1)$ & $49(2.0)$ & $2410(9.8)$ \\
\hline Diarrhea & $1534(90.3)$ & $156(9.2)$ & $8(0.5)$ & $1698(6.9)$ \\
\hline Nausea & $1231(84.7)$ & $210(14.5)$ & $12(0.8)$ & $1453(5.9)$ \\
\hline Dizziness/lightheadedness & $1108(83.1)$ & $183(13.7)$ & $42(3.2)$ & $1333(5.4)$ \\
\hline Vomiting & $242(50.1)$ & $219(45.3)$ & $22(4.6)$ & $483(2.0)$ \\
\hline
\end{tabular}

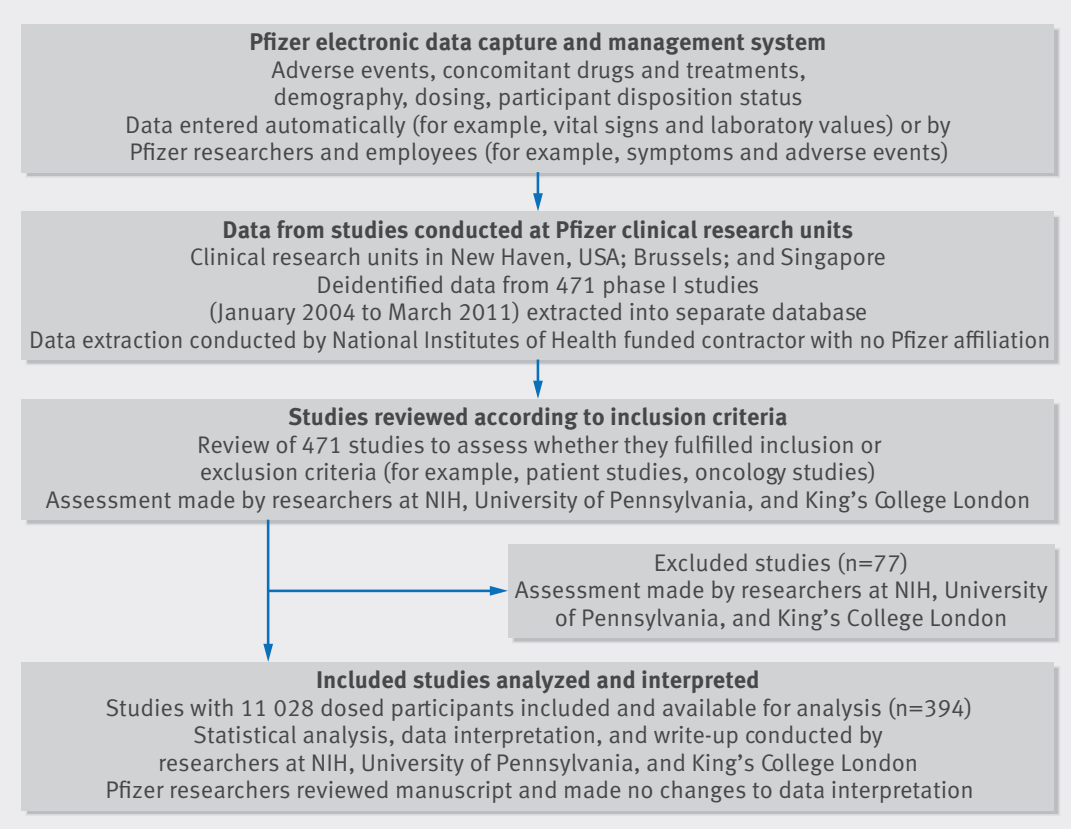

Flow of participants through study study drugs receiving placebo. During treatment with placebo, $2528(10.3 \%)$ of all adverse events occurred (table 4). Healthy participants who received placebo were just as likely to experience mild and moderate adverse events as those who received study drugs (mild: for placebo: 4813 of 5748 (83.7\%) adverse events versus for active drug 18632 of 22115 (84.3\%); moderate: for placebo 313 of 2528 (12.4\%) v 3235 of $22115(14.6 \%))$. However, 208 (1.1\%) participants receiving active drug and seven $(0.3 \%)$ receiving placebo experienced severe adverse events $(\mathrm{P}<0.001$, table 4).

\section{Serious adverse events}

Serious adverse events are defined by the FDA as causing death, a life threatening event, a persistent or major disability, admission to hospital or prolongation of an existing hospital admission, or congenital anomaly or birth defect. ${ }^{17}$ A total of 34 serious adverse events occurred $(0.31 \%$ of dosed participants, table 5$)$. One serious adverse event occurred among the biologics tested $(0.27 \%)$. Table 6 provides the details for each serious adverse event from the forms submitted to the FDA and the computer records maintained by Pfizer.

No deaths or persistent or major disabilities occurred (tables 5 and 6). Four serious adverse events were experienced by participants receiving a placebo and four occurred on the first day of the study. Half were deemed related to the study, with 11 (32\%) serious adverse events caused by the study drug itself and seven (21\%) caused by surgical or medical interventions related to the trial, such as spinal taps (table 6). Two involved fetal exposure to drugs but no known birth defects resulted. Some serious adverse events were unrelated to the drug, such as dengue hemorrhagic fever and appendicitis.

\section{Predictors of adverse events}

Among participant or study characteristics that might be associated with a greater risk of adverse events, significant differences were observed between men and women, with women significantly more likely than men to experience an adverse event $(80 \% v 62 \%, \mathrm{P}<0.001)$. Participants with a history of alcohol consumption were more likely to experience an adverse event than those with no such history (69\% v 60\%, P<0.001); however, the same was not true for smoking history $(64 \%$ in both groups, $\mathrm{P}=0.88$ ). Adverse events did not differ between those who had participated in previous research $(63 \%)$ and those who had not $(65 \%, P=0.10$, table 4).

Phase I studies with investigational agents were more likely to have adverse events than previous FDA approved agents $(65 \%$ v 55\%, $\mathrm{P}<0.001)$. Drugs associated with neuropsychiatric, gynecological, and gastrointestinal studies caused significantly more adverse events per participants dosed than the study drugs for other types of studies, whereas rheumato and cardiovascular study drugs caused significantly fewer adverse events per participants (table 3). 


\begin{tabular}{|c|c|c|c|c|}
\hline \multirow[b]{2}{*}{ Characteristic of studies } & \multicolumn{3}{|c|}{ No (\%) of adverse events } & \multirow[b]{2}{*}{ Total No (\%) } \\
\hline & Mild & Moderate & Severe & \\
\hline Total & $20840(84.6)$ & 3548 (14.4) & $255(1.0)$ & 24643 \\
\hline Caused by study drug* & $16238(86.9)$ & $2250(12.0)$ & $208(1.1)$ & $18696(75.9) \dagger$ \\
\hline Before dosing with research drug & $475(69.3)$ & $205(29.9)$ & $5(0.7)$ & $685(2.8)$ \\
\hline First day of study & $3952(86.0)$ & $588(12.8)$ & $56(1.2)$ & $4596(18.7)$ \\
\hline \multicolumn{5}{|l|}{ Prior participation: } \\
\hline Yes & $16027(84.8)$ & $2678(14.2)$ & $190(1.0)$ & $18895(76.7)$ \\
\hline No & $4813(83.7)$ & $870(15.1)$ & $65(1.1)$ & $5748(23.3)$ \\
\hline \multicolumn{5}{|l|}{ Treatment group: } \\
\hline Active drug & $18632(84.3)$ & $3235(14.6)$ & $248(1.1)$ & $22115(89.7)$ \\
\hline Placebo & $2208(87.3)$ & $313(12.4)$ & $7(0.3)$ & $2528(10.3)$ \\
\hline \multicolumn{5}{|l|}{ Blinding of trial: } \\
\hline Yes & $10230(81.7)$ & $2140(17.1)$ & $156(1.3)$ & $12526(50.8)$ \\
\hline No & $10605(87.6)$ & $1407(11.6)$ & $99(0.8)$ & $12111(49.2)$ \\
\hline \multicolumn{5}{|l|}{ Action taken: } \\
\hline None & $20743(85.2)$ & $3405(14.0)$ & $187(0.8)$ & $24335(98.7)$ \\
\hline Temporary discontinuation: no treatment & $6(25.0)$ & $17(70.8)$ & $1(4.2)$ & $24(0.1)$ \\
\hline Temporary discontinuation: treatment & $0(0)$ & $7(87.5)$ & $1(12.5)$ & $8(<0.1)$ \\
\hline Permanent discontinuation: no treatment & $72(37.9)$ & $72(37.9)$ & $46(24.2)$ & $190(0.8)$ \\
\hline Permanent discontinuation: treatment & 14 (20.9) & $37(55.2)$ & $16(23.9)$ & $67(0.3)$ \\
\hline
\end{tabular}

${ }^{*}$ As assessed by principal investigator.

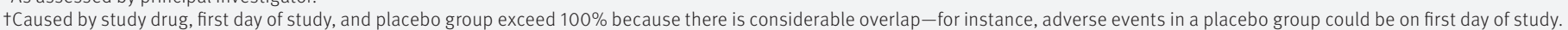

Adverse events differed among sites, with the most recorded by Belgium (75\%), followed by the United States $(65 \%)$ and Singapore $(50 \%, P<0.001)$. Within the US site, race was a significant predictor of adverse events, with Asians (including individuals with both south and east Asian ethnicity) (55\%) significantly less likely to experience an adverse event than white people (69\%), black people (63\%), and Hispanic people (66\%) $(\mathrm{P}<0.001)$.

\section{Discussion}

In this study we identified 34 (0.31\%) serious adverse events in more than 11000 healthy participants who received the study drugs in non-oncology phase I research studies, involving over 4500 unique individuals. No deaths, persistent disability, or life threatening events occurred. More than one third of all participants experienced no adverse events, about a quarter of all

\begin{tabular}{|c|c|c|c|}
\hline \multirow[b]{2}{*}{ Characteristic of studies } & \multicolumn{2}{|c|}{$\begin{array}{l}\text { No of serious adverse events } \\
\text { by agent type }\end{array}$} & \multirow[b]{2}{*}{ Total No } \\
\hline & Small molecule & Biologic & \\
\hline Total & 33 & 1 & 34 \\
\hline Caused by study drug* & 10 & 1 & 11 \\
\hline First day of study & 4 & 0 & 4 \\
\hline Placebo group & 4 & 0 & 4 \\
\hline Death & 0 & 0 & 0 \\
\hline Life threatening event & 0 & 0 & 0 \\
\hline Extended stay in phase I unit or hospital admission & 26 & 1 & 27 \\
\hline Medical or surgical interventiontł & 11 & 1 & 12 \\
\hline Persistent or major disability or incapacity & 0 & 0 & 0 \\
\hline Birth defect or anomaly & 0 & 0 & 0 \\
\hline
\end{tabular}

*As assessed by principal investigator.

tFor example, blood patch for spinal tap.

‡Requiring a medical or surgical procedure is not a criterion for designating an adverse event as serious. adverse events were judged to be unrelated to the study drug, and the majority of adverse events were classified as mild.

Six points from this study need to be highlighted. Firstly, this is the largest evaluation of the risks of non-oncology phase I trials, covering 394 trials with over 11000 participants who received the study drugs; seven times larger than any previous assessment. ${ }^{11-16}$ The study also deals with the limitations of previous studies. There was no selectivity; the study reports all the phase I data for nearly seven years involving healthy volunteers of a pharmaceutical company from phase I research facilities on three continents, and including data from studies in which drug development was terminated. Data on adverse events in this study are not based on investigator surveys but on the electronic medical records and case reports filed with the FDA; these data were collected at all three study centers in the same comprehensive and standardized manner. Importantly, the data were analyzed and interpreted by academic researchers with no financial links to pharmaceutical companies.

Secondly, the ethics of phase I trials in healthy participants have been questioned, partly because they are claimed to pose high risks of serious harms and offer no direct clinical benefits to participants. ${ }^{2-6}$ Over one third of participants in this study experienced no adverse events. Of the $64 \%$ of participants who did, the majority (nearly 85\%) of adverse events were mild. Overall we found low levels of severe and serious adverse events $-1.0 \%$ and $0.31 \%$, respectively. One explanation is that the dose escalation of phase I trials begins at subtherapeutic levels based on animal studies. This means that many participants received doses of study drug that were significantly below the estimated therapeutic level, which minimizes the risks of severe and 


\begin{tabular}{|c|c|c|c|c|c|}
\hline $\begin{array}{l}\text { Age (years) } \\
\text { and sex }\end{array}$ & $\begin{array}{l}\text { Type of research } \\
\text { agent }\end{array}$ & Characteristic of adverse events & $\begin{array}{l}\text { Relation to } \\
\text { research agent }\end{array}$ & $\begin{array}{l}\text { Relation to research } \\
\text { procedures }\end{array}$ & Intervention \\
\hline 23 female & Cardiovascular & Pregnancy & Unrelated & Unrelated & $\begin{array}{l}\text { Elective termination. Reporting process } \\
\text { follows serious adverse event process* }\end{array}$ \\
\hline 47 male & Neuropsychiatric & Volvulus & Unrelated & Unrelated & Hospital admission and sigmoidectomy \\
\hline 42 male & Cardiovascular & $\begin{array}{l}\text { Atypical chest pain with right shoulder pain } \\
\text { radiating to right arm and chest }\end{array}$ & Unrelated & Unrelated & $\begin{array}{l}\text { Admission to hospital and myocardial } \\
\text { infarction ruled out }\end{array}$ \\
\hline 41 male & $\begin{array}{l}\text { Infectious disease } \\
\text { (placebo) }\end{array}$ & Blurred vision and flashing lights days after drug & Unrelated & Unrelated & Detached retina treated with surgery \\
\hline 31 male & Neuropsychiatric & Appendicitis & Unrelated & Unrelated & Admission to hospital and appendectomy \\
\hline 26 male & Gynecological & Increased muscle enzymes & Unrelated & Unrelated & Admission to hospital for rhabdomyolysis \\
\hline 30 male & $\begin{array}{l}\text { Infectious disease } \\
\text { (placebo) }\end{array}$ & $\begin{array}{l}\text { Increased muscle enzymes seven days after last } \\
\text { drug dose }\end{array}$ & Unrelated & Unrelated & Admission to hospital \\
\hline 22 male & Cardiovascular & Fevers and sweats & Unrelated & Unrelated & $\begin{array}{l}\text { Admission to hospital for dengue fever } \\
\text { required cold compresses }\end{array}$ \\
\hline 25 male & Infectious disease & Syncope & Unrelated & Unrelated & $\begin{array}{l}\text { Admission to hospital with monitoring of } \\
\text { blood glucose }\end{array}$ \\
\hline 25 male & Infectious disease & $\begin{array}{l}\text { Burn on hands six days after last dosing. } \\
\text { House fire }\end{array}$ & Unrelated & Unrelated & Admission to hospital \\
\hline 24 female & Gynecological & Lightheadedness leading to a fainting spell & Unrelated & Unrelated & $\begin{array}{l}\text { Admission to hospital with monitoring of } \\
\text { blood pressure and blood glucose with } \\
\text { computed tomography scan and additional } \\
\text { laboratory tests }\end{array}$ \\
\hline 34 female & $\begin{array}{l}\text { Infectious disease } \\
\text { (placebo) }\end{array}$ & Joint pain & Unrelated & Unrelated & $\begin{array}{l}\text { Admission to hospital with ultrasound scan } \\
\text { of joint, additional laboratory tests, and } \\
\text { follow-up with general practitioner }\end{array}$ \\
\hline 23 male & Infectious disease & Tendon rupture from a bicycle incident & Unrelated & Unrelated & Surgical repair of tendon \\
\hline 29 male & Infectious disease & Abscess in throat & Unrelated & Unrelated & $\begin{array}{l}\text { Admission to hospital with antibiotics and } \\
\text { additional laboratory tests }\end{array}$ \\
\hline 28 male & Neuropsychiatric & Acute psychosis & Unrelated & Unrelated & Admission to hospital \\
\hline 35 male & Pulmonary & Fractured left arm from a bicycle incident & Unrelated & Unrelated & Admission to hospital with casting of arm \\
\hline 21 male & Neuropsychiatric & Lumbar puncture back ache & Unrelated & Related & Prolonged stay in research unit \\
\hline 23 male & Neuropsychiatric & Lumbar puncture headache & Unrelated & Related & $\begin{array}{l}\text { Prolonged stay in research unit and blood } \\
\text { patch }\end{array}$ \\
\hline 41 male & Neuropsychiatric & Arterial line trauma and pain in wrist and thumb & Unrelated & Related & $\begin{array}{l}\text { Prolonged stay in research unit with } \\
\text { vascular surgery evaluation. }\end{array}$ \\
\hline 19 male & Neuropsychiatric & Lumbar puncture headache & Unrelated & Related & $\begin{array}{l}\text { Prolonged stay in research unit and blood } \\
\text { patch }\end{array}$ \\
\hline 23 male & Neuropsychiatric & $\begin{array}{l}\text { Headache after spinal tap before any research } \\
\text { drug was administered }\end{array}$ & Unrelated & Related & Prolonged stay in research unit \\
\hline 25 male & Neuropsychiatric & Headache and vomiting after spinal tap & Unrelated & Related & $\begin{array}{l}\text { Admission to hospital ruled out myocardial } \\
\text { infarction and meningitis }\end{array}$ \\
\hline 35 male & Neuropsychiatric & Wrist pain after arterial line placement & Unrelated & Related & Admission to hospital for one day \\
\hline 32 male & Neuropsychiatric & Headache post spinal tap & Unrelated & Related & Prolonged stay in research unit \\
\hline 28 male & Rheumatological & Fevers, headache, nausea & Related & Unrelated & $\begin{array}{l}\text { Admission to hospital with aseptic } \\
\text { meningitis }\end{array}$ \\
\hline 52 female & Infectious disease & $\begin{array}{l}\text { Increased liver enzymes with fever and epigastric } \\
\text { pain }\end{array}$ & Related & Unrelated & Admission to hospital for two days \\
\hline 45 male & Infectious disease & $\begin{array}{l}\text { Elevations on anterolateral electrocardiograph } \\
\text { leads }\end{array}$ & Related & Unrelated & $\begin{array}{l}\text { Admission to hospital to be ruled out for } \\
\text { myocardial infarction }\end{array}$ \\
\hline 36 male & Infectious disease & $\begin{array}{l}\text { Abdominal pain and cramping with heme } \\
\text { positive diarrhea and increased white blood cell } \\
\text { count }\end{array}$ & Related & Unrelated & $\begin{array}{l}\text { Admission to hospital and treated for } \\
\text { pancolitis }\end{array}$ \\
\hline 27 male & Infectious disease & $\begin{array}{l}\text { Flu-like syndrome with fever with lymphopenia, } \\
\text { increased partial thromboplastin time, and } \\
\text { increase interleukin } 6 \text { levels }\end{array}$ & Related & Unrelated & $\begin{array}{l}\text { Monitored with additional laboratory tests, } \\
\text { vital sign measurements, and } \\
\text { electrocardiography }\end{array}$ \\
\hline 53 female & Infectious disease & $\begin{array}{l}\text { Flu like syndrome with diarrhea with fever, } \\
\text { hypotension, leukopenia and increase interleukin } \\
6 \text { levels }\end{array}$ & Related & Unrelated & $\begin{array}{l}\text { Treated for hypotension with fluids, } \\
\text { laboratory tests, and vital sign } \\
\text { measurements }\end{array}$ \\
\hline 26 female & Infectious disease & Increased liver enzyme levels & Related & Unrelated & $\begin{array}{l}\text { Admission to hospital with additional } \\
\text { laboratory tests. }\end{array}$ \\
\hline 32 female & Gynecological & $\begin{array}{l}\text { Pregnancy after drug dosing leading to fetal } \\
\text { exposure to drug }\end{array}$ & Related & Unrelated & $\begin{array}{l}\text { Carried to term with no abnormalities. } \\
\text { Reporting process follows serious adverse } \\
\text { events process* }\end{array}$ \\
\hline 55 female & $\begin{array}{l}\text { Infectious disease } \\
\text { (placebo) }\end{array}$ & Vaginal bleeding & Relatedt & Unrelated & $\begin{array}{l}\text { Admission to hospital with vaginal } \\
\text { hysterectomy }\end{array}$ \\
\hline 41 male & $\begin{array}{l}\text { Cardiovascular } \\
\text { (placebo) }\end{array}$ & Increased liver enzyme levels & Related $\dagger$ & Unrelated & $\begin{array}{l}\text { Admission to hospital with evaluation for } \\
\text { gallstones }\end{array}$ \\
\hline
\end{tabular}

*Pregnancy is not a criterion for serious adverse events but the reporting requirement is the same.

tDetermination that adverse event was related to study drug was made by team of investigators before unblinding of data indicating whether the participant was receiving placebo or study drug. 
serious adverse events. In addition, about a quarter of the non-oncology phase I research studies involved drugs already FDA approved.

Thirdly, a substantial proportion of the adverse events reported in these non-oncology phase I trialsincluding the serious adverse events-were judged unrelated to the study agent or study procedures. Over $10 \%$ of the adverse events occurred in participants receiving placebos. Indeed, $80 \%$ of participants receiving placebo experienced a mild adverse event and $0.3 \%$ experienced a severe adverse event. Nearly $20 \%$ of the adverse events occurred on the first day of the study. These are often thought to be related to changes in behavior required as part of the study, such as the withdrawal from smoking and drinking alcohol or caffeinated beverages, rather than from the study drug, which is in a low concentration on the first day of dosing. Equally, some serious adverse events, such as dengue hemorrhagic fever from a mosquito bite, are unrelated to the study drug or procedures.

Fourthly, adverse events differed significantly between men and women. This might be related to the reported tendency of women to more often experience or to report adverse events. ${ }^{18} 19$ It also might be related to the higher rates of adverse events in gynecological studies, which enroll women. Tests of neuropsychiatric, gastrointestinal, and gynecological study drugs were associated with more adverse events (with a rate of severe adverse events at $2 \%$ ). Finally, only $11 \%$ of participants were women, which might have skewed the statistical analysis.

There are several potential explanations for the lack of women in these studies. In many phase I studies, women of childbearing potential are excluded because there is a lack of fetal toxicity data in animals presenting unknown risks to an embryo or to a woman's reproductive system. In addition, most participants, including women, were in their late 20 s or early 30s, the prime time for parenthood. Since women are frequently the primary caregivers, needing to be away from children for a prolonged period may make it difficult for some women to participate in these types of studies.

Fifthly, many commentators express ethical concerns about the vulnerability of participants in phase I research. The typical participant in non-oncology phase I research studies in this sample was a man in his late 20 s or early 30 s who had participated in a previous research study. This suggests that participants were not inexperienced about the nature of biomedical research or phase I research studies. In addition, while payment for participants may raise concerns about voluntariness, research suggests that those who are paid to participate read informed consent documents carefully and have greater understanding of research risks. ${ }^{20} 21$ Our data also suggest that participants in multiple studies report adverse events at the same rate as volunteers who participate in only one research study.

Finally, some may worry that these data may be unreliable because the adverse events were determined and classified by investigators from the pharmaceutical company and, some may argue, they have a strong interest in reporting fewer adverse events. Data on all serious adverse events are submitted to and validated by regulatory authorities such as the FDA. In addition, the fact that over 24000 adverse events were reported from mild to severe speaks against this claim. Furthermore, the informed consent documents given to participants encourage them at multiple places to report changes in health "however minor." Also, determinations of causality were made before unblinding of whether the participant was receiving placebo or the study drug, and all the serious adverse events were reported to the FDA and verified by them. Importantly, and contrary to the common concern, it is not in the interest of the investigators or the pharmaceutical company to minimize recording of adverse events in phase I studies. Study drugs that are associated with high and serious adverse events need to be identified early and quickly, so that determinations can be made about whether to terminate drug development or conduct additional clinical studies. Phase II and III trials are expensive. Terminating a drug in phase II or III because of safety or adverse effects that were ignored or hidden in phase I is a costly mistake. Finally, salaries or bonuses for researchers of phase I trials do not depend on the outcomes of the studies. Thus, phase I investigators at Pfizer do not have a personal financial interest in suppressing the reporting of adverse events. None the less, whatever bias in the reporting and classification of adverse events exists could only be eliminated by an independent assessment at the time that each adverse event was reported-a logistically complex and expensive set-up.

\section{Limitations of this study}

This study has several limitations. Firstly, the results may not be generalizable. Although this study was seven times the size of any previous study of non-oncology phase I trials, the data come from a single pharmaceutical company. The data may not generalize to the phase I trials of other companies, research contract organizations, or publicly funded phase I units. They may not generalize to the type and range of non-oncology drugs being studied by other pharmaceutical or biotechnology companies or research institutions. Before 2011, Pfizer was developing few biological agents, and thus this sample included few studies of biological agents. Tackling this limitation requires more transparency from these study sponsors on their phase I data. Secondly, with high proportions of men, black people, and participants who enrolled in multiple studies, there is no external validity for these phase 1 data. However, such studies are by design small because they aim to assess initial safety and not to generate externally validated safety data. Thirdly, participants were followed for 30 days after the final dosing or until the drug was down to the fifth half life. It is possible that longer term adverse events occurred after 30 days. Finally, given the low number of serious adverse events and three different 
sites, it is not possible to determine whether race, ethnicity, sex, or other factors could affect the most serious outcomes.

\section{Conclusion}

A key ethical concern about non-oncology phase I trials rests on the idea that they pose high risks of serious harm to healthy participants who cannot receive clinical benefit from the study drugs. This study of over 11000 participants who received study drugs largely ally these concerns and provides context and quantification of the risks of phase I studies. One third of all participants never experienced a single adverse event. While $64 \%$ of participants experienced adverse events, the majority-nearly $85 \%$-were mild and many occurred either while receiving placebo or before the study drug was administered. Overall, there were three serious adverse events for every 1000 participants, with several occurring with placebo, and others judged unrelated to the study drug or a study procedure. These results may not apply to other types of phase I studies, especially those with biological agents. Concerns about the high risks of serious harms in non-oncology phase I trials do not seem to be borne out.

We thank Jean Paul Hoffman for data extraction.

Contributors: EJE, AR, and DW conceived and designed the study and are the guarantors. GB, KM, and NBG acquired and analysed the data. EJE, NBG, AR, and DW interpreted the data. EJE drafted the manuscript. $\mathrm{GB}, \mathrm{KM}, \mathrm{NBG}, \mathrm{AR}$, and DW critically reviewed the manuscript. All authors approved the final version of the manuscript. The views expressed are those of the authors. They do not represent the position or policy of the NIH, DHHS, US government, or Pfizer. AR received funding from the Swiss National Science Foundation (PAO0B-117505/1 and PA0033-117502/2). Pfizer made the data available, provided guidance on how the data were collected, provided insights into the conduct of phase I research, and covered the salaries of the employees involved in each trial and in this project. Pfizer had an opportunity to review the manuscript but made no changes to the data interpretation.

Funding: This study was funded, in part by NIH intramural research funds and in part by funds from the Department of Medical Ethics and Health Policy of the Perelman School of Medicine, University of Pennsylvania. The researchers from NIH, University of Pennsylvania, and King's College London were independent of Pfizer and had no financial compensation from Pfizer. NBG was awarded a Pfizer grant that ended in 2009. The two Pfizer employees were paid by Pfizer. AR received funding from the Swiss National Science Foundation (PA00B-117505/1 and PA0033-117502/2). Pfizer provided no specific financial support for this study.

Competing interests: All authors have completed the ICMIE uniform disclosure form at http://www.icmje.org/coi_disclosure.pdf and declare: GB and KM are employees of Pfizer. NBG was awarded a Pfizer grant that ended in 2009; the non-Pfizer researchers have no financial ties-past or present-to Pfizer except for the statistician (NG) who participated in one Pfizer funded study that ended in 2009; no other relationships or activities that could appear to have influenced the submitted work.

Ethical approval: This study was deemed exempt from institutional review by the NIH because it involved the analysis of existing, stored, and deidentified data.
Data sharing: Data are available on request from the corresponding author atvp-global@upenn.edu.

Transparency: The lead author (EJE) affirms that the manuscript is an honest, accurate and transparent account of the study being reported. No important aspect of the study has been omitted. No discrepancies are withheld.

This is an Open Access article distributed in accordance with the Creative Commons Attribution Non Commercial (CC BY-NC 4.0) license, which permits others to distribute, remix, adapt, build upon this work non-commercially, and license their derivative works on different terms, provided the original work is properly cited and the use is non-commercial. See: http://creativecommons.org/licenses/ by-nc/4.0/.

1 Emanuel EJ, Wendler D, Grady C. What makes research ethical? JAMA 2000;283;2701-11.

2 Lemmens T, Elliott C. Justice for the professional guinea pig. Am J Bioethics 2001;1:51-3.

3 Shamoo AE, Resnick DB. Strategies to minimize risks and exploitation in phase one trials on health subjects. Am J Bioethics 2006;6:W1-13.

4 Elliott C, Abadie R. Exploiting a research underclass in phase I clinical trials. N Engl I Med 2008;358:2316-7.

5 Fisher JA. Medical research for hire: the political economy of pharmaceutical clinical trials. Rutgers University Press, 2009

6 Kass NE, Myers R, Fuchs EJ, et al. Balancing justice and autonomy in clinical research with health volunteers. Clin Pharmacol Ther 2007;82:219-27.

7 Fisher JA. Feeding and bleeding: the institutional banalization of risk to healthy volunteers in phase 1 pharmaceutical clinical trials. Science Technology Human Values 2015;40:199-226. http://sth.sagepub. com/content/early/2014/10/15/0162243914554838.abstract.

8 Rosenthal E. When drug trials go horribly wrong. New York Times 2006 Apr 7. www.nytimes.com/2006/04/07/world/europe/07ihtdrug.html?pagewanted=all\&_r=0.

9 Sheridan C. TeGenero fiasco prompts regulatory rethink. Nat Biotechnol 2006;24:475-6.

10 Emanuel EJ, Miller FG. Money and distorted ethical judgment about research: an ethical assessment of the TeGenero TGN1412 Trial. Am J Bioethics 2007;7:76-81.

11 Horstmann E, McCabe MS, Grochow L, et al. Risks and benefits of phase I oncology trials, 1991 through 2002. N Engl / Med 2005;352:895-904.

12 Roberts TG, Goulart BH, Squitieri L, et al. Trends in the risks and benefits to patients with cancer participating in phase 1 clinical trials. JAMA 2004;292:2130-40.

13 Kumagai Y, Fukazawa I, Momma T, et al. A nationwide survey on serious adverse events in healthy volunteer studies in Japan. Clin Pharmcol Ther 2006;79:P71.

14 Lutfullin A, Kuhlmann J, Wensing G. Adverse events in volunteers participating in phase I clinical trials: a single center five year survey in 1,559 subjects. Int J Clin Pharmacol Ther 2005;43:217-26.

15 Sibille M, Deigat N, Janin A, et al. Adverse events in phase I studies: a report in 1015 healthy volunteers. Eur J Clin Parmacol 1998:54:13-20.

16 Orme M, Harry J, Routledge P, et al. Health volunteer studies in Great Britain: the results of a survey into 12 month activity in this field. Br/Clin Pharmacol 1989:27:125-33.

17 Title 21 Code of Federal Regulations part 321, subpart B, section 32(a). Investigational new drug applications, IND safety reporting. www.accessdata.fda.gov/scripts/cdrh/cfdocs/cfcfr/CFRSearch. $\mathrm{cfm} ? \mathrm{fr}=312.32$.

18 Nicolson TJ, Mellor HR, Roberts RR. Gender differences in drug toxicity. Trends Pharmacol Sci 2010;31:108-14.

19 Martin RM, Biswas PN, Fremantle SN, et al. Age and sex distribution of suspected adverse drug reactions to newly marketed drugs in general practice in England: analysis of 48 cohort studies Br J Clin Pharmacol 1998:46:505-11.

20 Cryder CE, London AJ, Volpp KG, et al. Informative inducement: study payment as a signal of risk. Soc Sci Med 2010;70:455-64.

21 Stunkel L, Benson M, McLellan L, et al. Comprehension and informed consent: assessing the effect of a short consent form. IRB 2010;32:1-9.

(c) BMJ Publishing Group Ltd 2015 